\title{
Testing the UIP Hypothesis-Using Data from Partially Dollarized Developing Countries
}

\author{
Andualem Mengistu ${ }^{1}$ \\ ${ }^{1}$ Stockholm School of Economics, Sweden \\ Correspondence: Andualem Mengistu, Stockholm School of Economics, Department of Economics, Sveavägen \\ 65, 11383, Sweden. E-mail: andualem.mengistu@hhs.se
}

Received: January 6, 2014

Accepted: January 21, 2014

Online Published: March 25, 2014

doi:10.5539/ijef.v6n4p135

URL: http://dx.doi.org/10.5539/ijef.v6n4p135

\begin{abstract}
Unlike studies relying on data from industrial countries, recent studies using data from partially dollarized developing countries have found a favorable result to the uncovered interest parity hypothesis (UIP). In this paper, we test the robustness of these results using data from partially dollarized countries with higher and more volatile inflation rate (Tanzania and Uganda) than the countries covered in previous literature on developing countries. We find that UIP does not hold in Uganda and Tanzania. In fact, unlike previous studies on developing countries, we find that the currency with the higher interest rate appreciates, i.e., there is a forward premium puzzle. We also find that the coefficients will be less biased if we use international dollar interest rates rather than domestic ones. This tells us that capital controls do not play much of a role in these countries. In addition, we test whether the higher liquidity of the currencies of trading partners will improve results in favor of UIP. The results do not provide a clear conclusion. We find less bias when using the Kenyan shilling and more bias when using the South African rand compared to the U.S. dollar.
\end{abstract}

Keywords: UIP, partial dollarization, developing countries, Uganda, Tanzania

\section{Introduction}

Uncovered interest parity (UIP) is the hypothesis that the difference in interest rates on two otherwise similar assets that have different currencies of denomination should compensate for expected depreciation of the currency with the higher interest rate.

There are several studies testing this hypothesis for developed countries. The main finding of these studies is that the UIP hypothesis is widely rejected (Note 1). In fact, higher yield of assets denominated in a currency forecasts an appreciation of that currency. This phenomenon is called the forward premium puzzle.

Financial liberalization and the resulting availability of data in the 1990's has allowed researchers to extend the test of the UIP hypothesis to emerging economies. Alper et al. (2009) (Note 2) provide a review of the UIP literature in emerging economies and concluded that most studies dealing with data from emerging countries have found more favorable results for the UIP hypothesis. In addition, results on the test of the UIP hypothesis using interest rate differentials may not be the appropriate method to estimate whether there is a forward premium puzzle (Frankel \& Poonawala, 2010). That is because, if covered interest rate parity (CIP) doesn't hold due to the presence of capital controls and default risk, interest differentials do not measure the forward premium. This problem is more severe in emerging countries where there may be more political barriers to arbitrage and default risk. To solve that problem, the authors used the difference between the forward exchange rate and the spot exchange rate instead of the interest rate differentials to measure forward premium. They find the forward market to be less biased in emerging markets than in developed countries.

One hypothesis as to why we find favorable results to the UIP hypothesis in emerging economies is that these countries are characterized by higher and more volatile inflation rates. The higher inflation level in emerging economies introduces a common trend in the interest rates and exchange rates, and this may overwhelm news effects, making it easier for investors to follow the path of the expected depreciation in these countries (Note $3)$.

Following the argument above and the fact that the economies of developing countries are characterized by higher average inflation rates and higher inflation volatility than emerging economies, one expects to find a 
better empirical confirmation of the UIP hypothesis in developing countries. However, not many studies are undertaken using data developing countries. Among those that have studied the case of developing countries are Poghosyan et al. (2008) for Armenia and Melander (2009) for Bolivia. Poghosyan et al. (2008) used the fact that households and firms in Armenia can make a deposit in local banks in either the local or foreign currency. They find that UIP holds better than studies in developed and emerging economies. In particular, the authors find that coefficients in all horizons are above zero, i.e. no the forward premium puzzle. In addition, they find that deviations from the UIP are, on average, larger when using cross-country interest rate differences than when we use interest differences in the local financial markets, i.e., capital controls affect the bias in estimated coefficients.

Melander (2009) has done a similar analysis using data from April 1994-November 2006 in Bolivia. The author finds that there is no forward premium puzzle in Bolivia. In fact, UIP holds better in Bolivia than previous studies show in developed and emerging markets. He also finds that, unlike Chinn (2006), the bias increases as the maturity horizon increases. In addition, time varying risk premia, deviations from rational expectations, and the peso problem partially account for the observed deviation from the UIP hypothesis. However, these finding do not depend, in contrast to Poghosyan et al. (2008), on which interest rate differences (cross-country or local financial markets) are used.

In this paper we will extend the test of the UIP hypothesis to partially dollarized developing countries with higher and more volatile inflation rate (Tanzania and Uganda) than the countries studied in Poghosyan et al. (2008) and Melander (2009). Table 1 in the appendix to this chapter shows that Uganda and Tanzania have higher average inflation, higher inflation variance, lower GDP, and higher volume of transaction in terms of U.S. dollars in their financial markets than Armenia or Bolivia. As a result, data from Uganda and Tanzania are very useful to test the robustness of the results above.

We will address the following three issues in this paper. First, we test whether one finds less bias in UIP coefficients in developing countries by using local financial market data, i.e., interest rates of domestic assets denominated in both domestic and foreign assets. Second, we estimate UIP using cross-border data to investigate whether capital controls lead to bias in estimated UIP. Third, we investigate whether using currencies of trading partners rather than the U.S. dollar as reference currencies leads to a more favorable result to the UIP hypothesis. The reason one expects this claim to hold is that frequent and high volume trading with regional trading partners may increase the liquidity of the foreign exchange market between the currencies of these trading partners, which results in a more efficient foreign exchange market.

We have three main findings in this paper. First, we find that UIP does not hold. In fact, we cannot reject the presence of the forward premium puzzle for all horizons and both countries (Tanzania and Uganda). Second, the estimated coefficients in Tanzania using international dollar interest rates are less biased than the ones from domestic dollar interest rates. In other words, capital controls do not play much of a role in Tanzania. Third, we find that the bias in estimated coefficients depends on the reference currency under consideration. However, we cannot find a clear relationship between using a trading partner's currency and improved UIP coefficients.

The remainder of the paper is structured as follows: section 2 provides a brief discussion of theory and reviews the empirical literature. Section 3 discusses data and presents empirical results. Finally, section 4 summarizes and concludes the paper.

\section{The UIP Hypothesis: Theory and Literature Review}

In this section we first discuss the UIP hypothesis under the assumption of risk neutrality, rational expectations, and open capital markets. We then outline the implications for empirical findings of the failure of these assumptions.

The UIP hypothesis is a no-arbitrage condition between returns of domestic currency denominated and a foreign currency denominated assets. Specifically, if investors are risk neutral and have rational expectations and there are no political and/or financial barriers to arbitrage, holding two assets of similar maturity and liquidity but different currency of denominations should give similar yields. Formally, this hypothesis can be expressed as:

$$
\left(1+i_{t, k}\right)=\left(1+i_{t, k}^{f}\right)\left(S_{t, k}^{e} / S_{t}\right)
$$

Where $i_{t, k}$ is the interest rate on domestic assets denominated in domestic currency with maturity in $\mathrm{k}$ periods, $i_{t, k}^{f}$ is the interest rate on foreign assets denominated in foreign currency with maturity in k periods, is the expected spot exchange rate at time $\mathrm{t}+\mathrm{k}$, and $S t$ is the spot exchange rate at time $\mathrm{t}$ (Note 4 ). 
Taking logarithm of both sides of equation 1 and assuming rational expectations, we get the following expression:

$$
\ln \left(1+i_{t, k}\right)=\ln \left(1+i_{t, k}^{f}\right)+\ln \left(S_{t, k}^{e} / S_{t}\right)
$$

Assuming rational expectation and rearranging, we can write the UIP hypothesis as follows

$$
s_{t+k}-s_{t}=i_{t, k-i_{t, k}^{f}}^{f}+\varepsilon_{t+k}
$$

Where $s_{t+k} \equiv \ln \left(s_{t+k}\right)$ and $\varepsilon_{t+k}$ is a rational expectation error. Empirically, the test is whether the joint hypothesis $\alpha=0$ and $\beta=1$ holds in the following equation

$$
s_{t+k}-s_{t}=\alpha+\beta\left(i_{t, k}-i_{t, k}^{f}\right)+\varepsilon_{t+k}
$$

Below we discuss the implications to the estimated UIP coefficients of the failure of assumptions embedded in the UIP hypothesis. (Note 5)

First, the rational expectation hypothesis may fail. If market participants make systematic errors, the deviation of observed exchange rate from expected exchange rate will not be white noise. Rather, it will be correlated with information at time t. Specifically, if

$$
s_{t+k}=E_{t}\left(s_{t+k}\right)+\gamma_{t}+\varepsilon_{t+k}
$$

Where $\gamma_{t}$ depends on information at time t, equation 3 will then take the following form

$$
s_{t+k}-s_{t}=\alpha+\beta\left(i_{t, k}-i_{t, k}^{f}\right)+\gamma_{t}+\varepsilon_{t, k}
$$

Estimating $\beta$ using equation 3 will then lead to bias because $i_{t, k}-i_{t, k}^{f}$ and $\gamma_{t}$ may be correlated.

Second, investors may not be risk neutral. Risk-averse investors charge a premium for the risk of exchange rate movements. In that case, expected exchange rate will be different from the forward rate. We can express the risk premium as follows:

$$
\varphi_{t}=f_{t}^{k}-s_{t, k}^{e}
$$

This implies that equation 3 will have the following form:

$$
s_{t+k}-s_{t}=\alpha+\beta\left(i_{t, k}-i_{t, k}^{f}\right)-\varphi_{t}+\varepsilon_{t, k}
$$

As long as $\left(i_{t, k}-i_{t, k}^{f}\right)$ and $\varphi_{t}$ are correlated, there will be bias in the estimation of $\beta$ if we estimate it using equation 3 .

Third, there may be political or financial barriers for arbitrage. If the local interest rate is higher than the foreign interest rate but exchange rate is not expected to depreciate, capital will flow to the country until exchange rate appreciates enough and the arbitrage opportunity disappears. But if there are capital controls, it may not be possible to exploit the difference in interest rates between the two assets. As a result, the hypothesis in equation 3 will fail.

Notice that one implication of this observation is that covered interest rate parity (CIP) also fails. Therefore, one possible way to express the hypothesis in equation 3 to get an unbiased coefficient estimate is to use the forward rate instead of interest rate differences. The resulting equation will look as follows:

$$
s_{t+k}-s_{t}=\alpha+\beta\left(f_{t}^{k}-s_{t}\right)-\varphi_{t}+\varepsilon_{t, k}
$$

However, most developing countries do not have a forward exchange market. As a result, testing the UIP hypothesis using the forward premium is not a viable option. We need to find a way to use interest rate data but avoid the problem of barriers to arbitrage. To see this problem we rewrite equation 3 as follows

$$
s_{t+k}-s_{t}=\alpha+\beta\left(i_{t, k}-i_{t, k}^{f d}\right)+\beta\left(i_{t, k}^{f d} i_{t, k}^{f}\right)+\varepsilon_{t, k}
$$

Where $i_{t, k}^{f d}$ is return on a domestic asset denominated in foreign currency with maturity in k periods. The term $\left(i_{t, k}-i_{t, k}^{f d}\right)$ will be different from zero if there is country specific risk and/or there are capital controls. If there are capital controls, even if $i_{t, k}^{f d} \neq i_{t, k}^{f d}$, capital may not be able to move freely to use the arbitrage opportunity. A better test of the hypothesis will therefore be to test the following equation:

$$
s_{t+k^{-}} s_{t}=\alpha+\beta\left(i_{t, k}-i_{t, k}^{f d}\right)+\varepsilon_{t, k}
$$

This is the equation we will estimate in the domestic asset section of the paper.

\subsection{Review of the Empirical Literature}


There are several studies testing the UIP hypothesis for developed countries. (Note 6) The main finding of these studies is that the UIP hypothesis is widely rejected. In fact, higher yield of assets denominated in a currency forecasts an appreciation of that currency. This phenomenon is called the forward premium puzzle.

For instance, Chinn (2006) estimated an equation similar to 3 above for the exchange rate between the U.S. dollar and currencies of other G 7 countries (U.K., France, Germany, Japan, Italy, and Canada) for the period 1980-2000. He finds that the estimated beta is less than zero in all cases except the exchange rate between Italian Lira and the U.S. dollar and the average coefficient for the group is -0.8. In addition, he shows that this bias decreases when we consider longer time horizons. In particular, an estimation using a panel data of the aforementioned countries yields estimates ranging from about -0.76 at the three-month horizon to -0.54 at the 12-month horizon.

Financial liberalization and the resulting availability of data on emerging countries in the 1990's has allowed researchers to extend the test of the UIP hypothesis to these countries. One may expect a different result in the relationship between nominal interest rate differentials and exchange rate depreciation in emerging countries, compared to developed economies, because these countries are characterized by shallow financial markets, higher inflation rates, and higher inflation volatility. For instance, the higher inflation level in emerging economies introduces a common trend in the interest rates and exchange rates, and this may overwhelm the news effects, making it easier for foreign investors to follow the path of the expected depreciation in these countries.

Most studies dealing with data from emerging economies have found more favorable results for the UIP hypothesis, although the evidence is statistically not very strong. (Note 7) For instance, Bansal and Dahlquist (2000) show that, unlike the results in developed countries, one does not find a forward premium puzzle in emerging economies. In particular, lower GNP per capita and higher and more volatile inflation is associated with better performance of the UIP hypothesis. Flood and Rose (2001), on the other hand, find that the GNP of a country doesn't matter to the result on UIP. The difference in the results between these two studies may stem from the fact that the former used the period from 1976-1998 for developed countries, while they only used data from the 1990s for developing countries. The later, on the other hand, restrict their sample to the 1990s for both developed and developing countries. In the 199s several European countries suffered from speculative currency attacks. That and the different sample period used may account for the difference in the result. The drawback of these studies is that they both assume perfect capital mobility (i.e., they estimated equation 3 ) and they interpret any forward premium as the failure of the UIP hypothesis.

Frankel and Poonawala (2010) pointed out that results from the test of the UIP hypothesis using interest rate differentials might not be the appropriate method to estimate whether there is a forward premium puzzle. If CIP doesn't hold, due to the presence of capital controls and default risk, interest differentials do not measure the forward premium. This problem is more severe in emerging countries where there may be more political barriers to arbitrage and default risk. To solve that problem Frankel and Poonawala (2010) use the difference between the forward exchange rate and the spot exchange rate instead of the interest rate differentials (i.e. they estimate equation $4 \mathrm{c}$ ) to measure forward premium. They find the forward market to be less biased in emerging markets than in developed countries and re-established the Bansal and Dahlquist (2000) result.

Following the argument above and the fact that the economies of developing countries are characterized by higher average inflation rates and higher inflation volatility than emerging economies, one expects to find a better empirical confirmation of the UIP hypothesis in developing countries. However, due to the higher probability that covered interest rate parity may fail because of political barriers to arbitrage and the lack of data on forward markets not many studies are undertaken using data on developing countries.

Among those that have studied the case of developing countries are Poghosyan et al. (2008) for Armenia and Melander (2009) for Bolivia. Poghosyan et al. (2008) used the fact that households and firms in Armenia can make a deposit in local banks in either the local or a foreign currency (i.e., estimate equation $4 \mathrm{~d}$ ). They find that UIP holds better than in studies on developed and emerging economies. In particular, the authors find that coefficients in all horizons are above zero, i.e., there is no forward premium puzzle. In addition, they find that deviations from the UIP are, on average, larger when using cross-country interest rate difference than when we use interest differences in the local financial markets, i.e., capital controls affect the bias in estimated coefficients. Melander (2009) did a similar analysis (i.e. estimated equation 4d) using a weakly data covering the period April 1994-November 2006 in Bolivia. He finds that there is no forward premium puzzle in Bolivia. In fact, UIP holds better in Bolivia than even Poghosyan et al. (2008) have found for Armenia. He also finds that, unlike Chinn (2006), the bias increases as the maturity horizon increases. In particular, the estimated beta ranges from about 0.31 at the one-month horizon to 0.21 at the three-month horizon and 0.10 at the 12 -month horizon. In addition, 
time varying risk premia, deviations from rational expectations, and the peso problem partially account for the observed deviation from the UIP hypothesis. However, these finding do not depend, in contrast to the one in Poghosyan et al. (2008), on which interest rate differences (cross country or local financial markets) are used.

Most of the studies cited in this section test the UIP hypothesis using data from a given country's interest rate and currency and pair it with U.S. dollar and dollar interest rate. Very few studies have investigated the robustness of these results to a change in reference currencies. Chinn and Meredith (2005) estimated UIP for U.S., Germany, Japan, and Canada using the U.S. dollar and the Deutschmark as reference currencies and find similar coefficients in both cases. Hanim et al. (2011) estimated UIP for a panel of emerging economies using the U.S. dollar, the Japan yen and the Deutschmark as alternative reference currencies. They find that the estimated coefficients differ across reference currencies. However, the magnitude of the difference is very small.

\section{Data and Empirical Results}

\subsection{Data and Country Features}

Since the theory assumes market determined interest and exchange rates, we have to include periods in these countries where the markets for both interest rates and exchange rates are liberalized. In both Tanzania and Uganda, interest rates are fully liberalized and exchange rate is market determined since 1993 (Masawe, 2001; Musinguzi \& Katarikawe, 2001). Therefore, the periods we cover in this paper April 1999-August 2012 for Uganda and June 2002-February 2012 for Tanzania lie fully in the liberalized phase.

As shown in Bansal and Dahlquist (2000), the lower the GDP per capita, the higher the average inflation rate, and the higher the volatility of inflation rate, the more we reject the forward premium puzzle. Table A.1 in the appendix shows that both countries included in this paper have low GDP per capita and higher inflation volatility and higher average inflation compared to even other low income countries like Armenia and Bolivia. Therefore, one expects to reject the forward premium puzzle in these countries.

To estimate similar equations as in Poghosyan et al. (2008) and Melander (2009), we need domestic interest rate data denominated in domestic and foreign currency. To that end, in Tanzania we use monthly data on time deposit rates of one, two, and three months maturity in both the Tanzanian Shillings and the U.S. dollar. In Uganda we use demand deposit rates, in both local and foreign currency, as the one-month maturity interest rate. And we use saving deposits of appropriate maturity in both Ugandan Shillings and U.S. dollars for three, six, and 12 months maturity.

We would also like to check whether one gets a more favorable result to the UIP hypothesis by using interest and exchange rate data of a trading partner than the U.S. dollar. The reason one expects this claim to hold is that frequent and high volume trading with regional trading partners may increase the liquidity of the foreign exchange market between the currencies of these trading partners, which results in a more efficient foreign exchange market. We investigate this claim by using data from Kenya and South Africa, the biggest regional trading partners to Tanzania. In particular, we use monthly data of one month, three months, six months, and 12 month treasury rates of Tanzania, Kenya, South Africa, and the U.S. In Uganda all yields on local assets are stationary and thus cannot be cointegrated with yields of foreign assets. At the same time exchange rate depreciation (between Ugandan shillings and the currencies of the aforementioned countries) is stationary. As a result, UIP regression will not be valid econometrically. Therefore, our result for Uganda is restricted to a UIP regression using only domestic assets with different currency denomination. The sources for all interest rate and exchange rate data are central banks of the respective countries.

\subsection{Data Definition}

\subsubsection{Tanzania Local Assets}

Onemonth, threemonths, sixmonths, and twelvemonths are the differences between time deposit rates of one month, three months, six months, and 12 months maturity denominated in local currency and time deposit rates of one month, three months, six months, and 12 months maturity denominated in U.S. dollar offered by local banks.

\subsubsection{Tanzania Cross Country Assets}

Onemonth, threemonths, sixmonths, and twelvemonths are the difference between Tanzanian treasury rates of one month, three months, six months, and 12 months maturity denominated in Tanzanian shillings and treasury rates of one month, three months, six months, and 12 months maturity of the foreign country denominated in the foreign country's currency.

\subsubsection{Uganda Local Assets (Note 8)}


Onemonth, threemonths, sixmonths, and twelvemonths are the difference between saving rates of one month, three months, six months, maturity denominated in local currency and saving rates ofonel month, three months, six months, and twelve months maturity denominated in U.S. dollar offered by local banks.

\subsubsection{Exchange Rates}

Onemonth depreciation is depreciation of the local currency in a month, three month depreciation is depreciation of the local currency over three months, sixmonths depreciation is the depreciation of the local currency over six months, and twelve months depreciation is the depreciation of the local currency over twelve months.

\subsection{Empirical Results}

This section is divided into two subsections. In the first subsection, we discuss results from using local financial market data, i.e., interest rates of domestic assets denominated in both domestic and foreign currencies, and compare them with the ones in the literature. We then proceed to investigate what contributes to the bias in the estimated coefficients. In the second subsection, we estimate UIP using cross-country data. This will help U.S. investigate whether the bias depends on the dollar interest rate we use (domestic or international) and whether using currencies of trading partners rather than the U.S. dollar leads to a more favorable result to the UIP hypothesis. The reason one expects this claim to hold is that frequent and high volume trading with regional trading partners may increase the liquidity of the foreign exchange market between the currencies of these trading partners, which results in a more efficient foreign exchange market.

\subsubsection{Results from Local Financial Market Assets}

Before proceeding with estimating the UIP equation, we need to check the time series property of the data. In particular, exchange rate depreciation and differences between interest rates of different currency denomination should be integrated of the same order. Table 1 provides the results for unit root tests of: domestic asset interest rates denominated in Ugandan shillings and U.S. dollar, exchange rate between Ugandan shillings and U.S. dollar, Tanzanian Shillings and U.S. dollar, and exchange rate between Tanzanian Shillings and U.S. dollar. We find that the null hypothesis of unit root is always rejected for all variables by at least one of the tests.

Table 1. Unit root test local financial market assets

\begin{tabular}{lllll}
\hline \multirow{2}{*}{ Variable } & \multicolumn{2}{c}{ Uganda } & \multicolumn{2}{c}{ Tanzania } \\
& ADF statistics & PP statistics & ADF statistics & PP statistics \\
\hline \multirow{2}{*}{ Onemonth depreciation } & -6.85 & -9.239 & -9.856 & -9.832 \\
& 0 & 0 & 0 & 0 \\
Threemonths depreciation & -4.913 & -4.814 & -3.916 & -4.328 \\
\multirow{3}{*}{ Sixmonths depreciation } & 0 & 0 & -0.002 & 0 \\
Twelvemonth depreciation & -5.25 & -4.041 & -3.656 & -3.486 \\
& 0 & -0.001 & -0.005 & -0.008 \\
Onemonth & -3.109 & -2.708 & -2.67 & -2.585 \\
\multirow{2}{*}{ Threemonths } & -0.026 & -0.073 & -0.0794 & -0.096 \\
\multirow{2}{*}{ Sixmonths } & -5.419 & -9.595 & -4.024 & -3.785 \\
\multirow{2}{*}{ Twelvemonths } & -0.001 & 0 & -0.001 & -0.003 \\
& -3.044 & -3.744 & -2.761 & -2.399 \\
& -0.031 & -0.004 & -0.064 & -0.142 \\
& -3.154 & -3.823 & -3.301 & -2.875 \\
& -0.029 & -0.003 & -0.015 & -0.048 \\
\hline
\end{tabular}

Note. ADF statistics stands for the estimated beta coefficient in an augmented Dickey-Fuller test. PP statistics stands for the estimated beta coefficient in the Phillips perron statioanrity test. Values in parentheses are P-values.

Since exchange rate depreciation and interest rate differences are integrated of the same order (they are both stationary), we proceed to the issue of estimation. In this section we estimate equation $4 \mathrm{~d}$ to investigate if the UIP hypothesis holds better when we use data on domestic assets denominated in different currencies. Table 2 presents OLS estimation results with Newey-West standard errors. For all maturity ranges we reject the null hypothesis that $\alpha=0$ and $\beta=1$. In fact in all maturity horizons we find that the point estimates of $\beta$ are negative. 
i.e., we cannot reject the presence of the forward premium puzzle (i.e., $\beta<0$ ).

Table 2. UIP regression with domestic assets

\begin{tabular}{|c|c|c|c|c|c|}
\hline & \multirow{2}{*}{ Coefficients } & \multicolumn{4}{|c|}{ Forecast Horizons } \\
\hline & & Onemonth & Threemonths & Sixmonths & Twelvemonths \\
\hline \multirow{4}{*}{ Tanzania } & \multirow{2}{*}{$\alpha$} & $1.10^{* * *}$ & $3.86^{* * *}$ & $7.59 * * *$ & $13.76 * * *$ \\
\hline & & -0.36 & -1.23 & -2.46 & -4.42 \\
\hline & \multirow{2}{*}{$\beta$} & $-2.47 *$ & $-2.60 * *$ & $-2.09 *$ & $-1.71 *$ \\
\hline & & -1.51 & -1.34 & -1.18 & -0.98 \\
\hline \multirow{4}{*}{ Uganda } & \multirow{2}{*}{$\alpha$} & $0.36^{* *}$ & 1.14 & $2.15 * * *$ & $4.27 * * *$ \\
\hline & & -0.21 & -0.44 & -0.62 & -0.77 \\
\hline & \multirow{2}{*}{$\beta$} & -1.68 & $-2.14 * *$ & $-1.75^{* *}$ & $-1.45^{* *}$ \\
\hline & & -1.75 & -1.06 & -0.83 & -0.71 \\
\hline
\end{tabular}

Note. The results are found from OLS estimation, with Newey-West standard errors, of equation 4d. The values in parentheses are standard errors. $* * * * *, *$ Indicate significance at $1 \%, 5 \%, 10 \%$ significance level, respectively.

The results presented above are in contrast to results from previous studies that found larger (positive) point estimates and reject the forward premium puzzle for developing countries. For instance, for one month forecast horizon Poghosyan et al. (2008) find beta to be close to 0.9, Melander (2009) find it to be 0.31 and the average of emerging markets in Frankel and Poonawala (2010) is 0.152. (Note 9) We also find that as the maturity range increases, the bias (the forward premium) decreases. For instance, the coefficient on three months, six months, and twelve months maturity time deposit rate in Tanzania are $-2.603,-2.08$, and -1.712 respectively. This same pattern holds in Uganda as well. This finding is consistent with the results in Chinn (2006).

Two potential sources for failure of the UIP hypothesis discussed in the literature and pointed out in the theory section are failure of rational expectation hypothesis and time varying risk premia.

\subsubsection{Rational Expectation}

To investigate whether failure of rational expectations may explain the bias we find above, we use the suggestion of Froot and Thaler (1990) and run a regression of the following form.

$$
s_{t+k^{-}} s_{t}=\alpha+\beta\left(i_{t, k}-i_{t, k}^{f d}\right)+\sum_{j=1}^{n} \beta_{j}\left(i_{t, k-j} i_{t, k-j}^{f d}\right)+\varepsilon_{t, k}
$$

The idea is that, if all investors have rational expectations, then information from past periods is incorporated in their expectations and should not explain deviations from UIP. We find that coefficients on lags of interest rate differences in both countries at any maturity horizon are not statistically significant. The Wald test shows that we cannot reject the null hypothesis that all lag coefficients are zero. That may be because, as argued in Alper et al. (2009), higher inflation in developing countries generates predictable common trends in both exchange rate depreciation and interest rates.

\subsubsection{Time Varying Risk Premia}

As shown in the theory section, the estimated $\beta$ will be downward biased if there are time varying risk premia that are correlated with interest rates (equation $4 \mathrm{~d}$ ). We first test for time varying risk premia by checking whether errors from the regression cluster around. In other words, we say there are time varying risk premia if positive deviations from the regression follow higher deviation and negative deviations follow negative ones.

Table 3 presents results from Engel's LM test for heteroskedasticity. We find that, except the one-month maturity range in Tanzania, the errors are characterized by the presence of autoregressive heteroskedasticity. Therefore, we continue to test whether taking into account the presence of time varying risk premia will change the estimated coefficients in Table 2. 
Table 3. LM test for autoregressive conditional heteroskedasticity (ARCH)

\begin{tabular}{lllll}
\hline Country & Onemonth & Threemonths & Sixmonths & Twelvemonths \\
\hline \multirow{2}{*}{ Tanzania } & 2.64 & $34.778^{* * *}$ & $52.398^{* * *}$ & $60.379 * * *$ \\
& -0.267 & 0 & 0 & 0 \\
\multirow{2}{*}{ Uganda } & $2.82 *$ & $64.307 * * *$ & $88.312 * * *$ & $109.202 * * *$ \\
& -0.191 & 0 & 0 & 0 \\
\hline
\end{tabular}

Note. The null hypothesis is that there are no $\mathrm{ARCH}$ effects. Therefore, high chi-square values suggest that the error terms have Autoregressive conditional heteroskedasticity. In other words, volatility in errors tends to be clustered. The values in the parentheses are p-values. ***,**, Indicates that we reject the null hypothesis that the coefficient is greater than zero at $1 \%, 5 \%, 10 \%$ significance level, respectively.

Table 4 presents the results from the estimation of the following equation:

$$
s_{t, k}-S_{t}=\alpha+\beta\left(i_{t, k}-i_{t, k}^{f d}\right)+\gamma \sigma_{t}^{2}+\varepsilon_{t, k}
$$

Where $\sigma^{2}$ is meant to capture to the effect of the risk premia.

We find that, though the coefficients on risk premia are not statistically significant, the coefficients on UIP regression become less biased when we take into account the presence of time varying premia in Tanzania. For instance, the coefficient on three-month maturity time deposit rate increases from -2.603 to -0.453 when taking the role of risk premia. Similar effects can be found in six and twelve month maturity range. However, including time varying risk premia increases the bias in the estimated UIP coefficients in Uganda. For instance, the coefficient on three month maturity time deposit rate decreases from $-2.14 *$ to -3.54 . Similar trends also hold for longer horizons. This finding for Uganda is a puzzle because, as shown in equation $4 \mathrm{~b}, \beta$ will be downward biased if interest rates are correlated with time varying risk but we fail to include risk premia variable in the regression. But we find here that inclusion of the risk premia actually increases the bias.

Table 4. UIP regression with domestic assets taking into account risk premium

\begin{tabular}{lllllll}
\hline & \multicolumn{3}{c}{ GARCH $(1,1)$ model Tanzania } & \multicolumn{3}{c}{ GARCH $(1,1)$ model Uganda } \\
Coefficients & Threemonths & Sixmonths & Twelvemonths & Threemonths & Sixmonths & Twelvemonths \\
\hline \multirow{2}{*}{$\alpha$} & $2.07^{* * *}$ & $6.2^{* * *}$ & $13.77^{* * *}$ & -0.32 & $1.92^{* * *}$ & 0.67 \\
& -0.52 & -1.12 & -1.59 & -0.29 & -0.35 & -0.75 \\
$\beta$ & -0.45 & $-0.95^{* *}$ & $-1.02^{* * *}$ & $-3.54^{* * *}$ & $-1.54 * * *$ & $-2.75^{* * *}$ \\
& -0.54 & -0.49 & -0.32 & -1.35 & -0.56 & -0.61 \\
$\gamma$ & -0.002 & -0.028 & $-0.032^{*}$ & $0.018^{* * *}$ & 0.004 & 0.018 \\
& -0.02 & -0.024 & -0.019 & -0.005 & -0.008 & -0.012 \\
\hline
\end{tabular}

Note. The result is from an estimation of a symmetric GARCH $(1,1)$ with an assumption of a Gaussian distribution. The estimated equation looks as follows, $s_{t, k}-s_{t}=\alpha+\beta\left(i_{t, k}-i_{t, k}^{f d}\right)+\gamma \sigma_{t}^{2}+\varepsilon_{t, k}$. Note that we have not reported the variance equation $\left(\sigma_{t}^{2}=c o n+\theta \varepsilon_{t-1}^{2}+\varphi \sigma_{t-1}^{2}\right)$ here because it is not relevant to our analysis. The values in the parentheses are standard errors. $* * *, * *,{ }^{*}$ Indicate significance at $1 \%, 5 \%, 10 \%$ significance level, respectively.

\subsubsection{Results from Regressions Using Cross-Country Assets}

In this subsection we investigate two things. First, we use data on international dollar interest rates in order to compare the results with the ones we find by using domestic dollar interest rates in the previous subsection. This will give us an indication as to whether capital controls play a major role in explaining the estimated UIP coefficients. Second, we investigate whether which reference currency we use determines the estimated coefficients. We include exchange rates and assets denominated in terms of Kenyan shillings and South African rand in addition to U.S. dollars to examine this question. The results from this investigation will have implications about the role of liquidity in the foreign exchange market.

Since the data used in this section are cross-country data, the estimated UIP equation will be equation 3 . Before proceeding with estimating the UIP equation, we need to check the time series property of the data. In particular, exchange rate depreciation and differences between interest rates of different currency denomination should be integrated of the same order. Table 2 in the appendix to this chapter provides the results for unit root tests of: differences between Tanzanian treasury rates of one month, three months, six months, and 12 months maturity and similar maturity treasury rates of U.S., Kenya, and South Africa. It also shows the time series test for 
depreciation of the exchange rate between Tanzania shillings and U.S. dollar, Kenyan shillings, and South African rand. We find that the null hypothesis of unit root is always rejected for all variables by at least one of the tests (Note 10).

Table 5 presents OLS estimation results of equation 3 with Newey-West standard errors. Similar to the section above, for all maturity ranges we reject the null hypothesis that $\alpha=0$ and $\beta=1$. In fact, in all maturity horizons we find that the point estimates of $\beta$ are negative and we cannot reject the presence of the forward premium puzzle (i.e., $\beta<0$ ).

We also find that estimated $\beta$ using international dollar interest rates are less biased than the ones we find when we use data on domestic assets only. In particular, the coefficients for three and six months forecast horizons are -0.780 and -0.891 when we use international dollar interest rates (Table 5 row 1 ). The coefficients we get when we use domestic dollar interest rate for similar forecast horizons are -2.60 and -2.09 respectively. The fact that we do not get coefficients that are less biased when using domestic dollar interest rate tells U.S. that capital controls do not play a major role in the Tanzanian economy.

We have pointed out in the literature review section that studies that have investigated the robustness of the estimated coefficients for changes in reference currencies have found no difference when using data from industrial countries (Note 11) and very small differences in magnitude when using data from emerging market economies. (Note 12) These results may be because there is sufficiently liquid circulation of these alternative reference currencies in these countries. This may not be the case in developing countries where most of the currency exchanges take place to facilitate trade than for portfolio reasons. Below we check whether the potential increased liquidity in the foreign exchange market will lead to less bias in estimated $\beta$ by using data from trading partners. However, the results do not lead to a clear conclusion. For instance, for the three-month forecast horizon, the estimated $\beta$ for South African rand is -1.98 , which is more biased than for U.S. dollar $(-0.891)$. Yet we find that the estimated $\beta$ using Kenyan shillings for three months forecast horizon is -0.55 , which is less biased than the one we get when using the U.S. dollar. We therefore conclude that the deviation from UIP depends on which reference currency one uses. However, the difference cannot be explained by increases liquidity of trading partner's currency.

Table 5. UIP regression with cross-country assets

\begin{tabular}{lllll}
\hline \multicolumn{1}{c}{ Coefficients } & & \multicolumn{3}{c}{ Forecast horizon } \\
& & Threemonths & Sixmonths & Twelvemonths \\
\hline \multirow{2}{*}{ Tanzania Shillings } & $\alpha$ & $2.559^{* *}$ & $5.845^{* * *}$ & $10.406^{* * *}$ \\
U.S. dollar & & -1.001 & -1.452 & -2.336 \\
& $\beta$ & -0.78 & $-0.891^{*}$ & $-0.637^{* *}$ \\
& & -0.765 & -0.527 & -0.328 \\
Tanzania Shillings & $\alpha$ & $1.99^{* *}$ & $4.96^{* * *}$ & $9.89^{* * *}$ \\
South Africa rand & & -1.039 & $(1.775$ & -2.053 \\
& $\beta$ & $-1.82^{*}$ & $-1.98^{* *}$ & $-2.46^{* * *}$ \\
& & -1.064 & -0.914 & -0.383 \\
Tanzania Shillings & $\alpha$ & $1.42^{* * *}$ & $2.74^{* * *}$ & 5.39 \\
Kenya Shillings & & -0.527 & -0.724 & -0.953 \\
& \multirow{2}{*}{$\beta$} & $-0.58^{*}$ & $-0.55^{*}$ & $-0.61 * * *$ \\
& & -0.351 & -0.332 & -0.216 \\
\hline
\end{tabular}

Note. The results are found from OLS estimation, with Newey-West standard errors, of the following equation 3 . The values in the parentheses are standard errors. ${ }^{* *},{ }^{* *}, *$ Indicate significance at $1 \%, 5 \%$, and $10 \%$ significance level respectively.

\section{Conclusion}

In this paper we extend the test of the UIP hypotheses to partially dollarized developing countries with higher and more volatile inflation rate (Tanzania and Uganda) to investigate the robustness of results in the literature that find less bias in estimated UIP coefficients in developing countries. Specifically, we address the following three issues in this paper. First, we test whether one finds less bias in UIP coefficients in developing countries by using local financial market data, i.e., interest rates of domestic assets denominated in both domestic and foreign assets. Second, we estimate UIP using cross border data to investigate whether capital controls lead to bias in estimated UIP. Third, we investigate whether using currencies of trading partners rather than the U.S. dollar as 
reference currencies leads to a more favorable result to the UIP hypothesis. The reason one expects this claim to hold is that frequent and high volume trading with regional trading partners may increase the liquidity of the foreign exchange market between the currencies of these trading partners, which results in a more efficient foreign exchange market.

Empirical investigation of the three questions above leads us to the following three conclusions. First, we find that UIP does not hold. In fact, we cannot reject the presence of the forward premium puzzle, i.e., we find the estimated $\beta$ to be less than zero for all horizons and both countries (Tanzania and Uganda). Second, the estimated coefficients in Tanzania using international dollar interest rates are less biased than the ones from domestic dollar interest rates. In other words, capital controls do not play much of a role in Tanzania. Third, we find that the bias in estimated coefficients depends on the reference currency under consideration. However, we cannot find a clear relationship between using trading partner's currency and improved UIP coefficients. In particular, using assets denominated in Kenyan shillings leads to less bias in the estimated $\beta$ and using assets denominated in South African rand lead to more bias in the estimated $\beta$ than using data from U.S. dollar denominated assets.

In the literature review, we have seen that emerging and developing countries with higher and more volatile inflation rate have less biased $\beta$. Given that observation and the fact that Uganda and Tanzania have higher and more volatile inflation rate and low GDP, one would expect a positive estimated beta in these countries.

However, we find that the estimated $\beta$ are negative and statistically significant. One way to solve this puzzle may be to take into account that both Bolivia and Armenia have experienced hyperinflation in the last 30 years. Ehrmann and Tzamourani (2012) show that inflation memory in countries that experience high inflations fades after about 10 years. But for those countries that experience hyperinflation, the memory stays for a much longer period. If agents in countries that experience hyperinflation are more attentive to inflation, then they will form better expectations about movements of the exchange rate. As a result, we are less likely to observe a forward premium puzzle. We left this hypothesis as a conjecture because we do not have sufficient number of countries that have experienced hyperinflation in recent periods to test it empirically.

\section{References}

Alper, C., Ardic, O., \& Fendoglu, S. (2009). The economics of the uncovered interest parity condition for emerging markets. Journal of Economic Surveys, 1, 115-138. http://dx.doi.org/10.1111/j.1467-6419.2008.00558.x

Bansal, R., \& Dahlquist, M. (2000). The forward premium puzzle: Different tales from developed and emerging economies. Journal of International Economics, 51, 115-144. http://dx.doi.org/10.1016/S0022-1996(99)00039-2

Chin, M. D. (2013). Chinn-ITO. Retrieved from http: //web.pdx.edu/ ito/Chinn - Itow ebsite.htm

Chinn, M. D. (2006). The (partial) rehabilitation of interest rate parity in the floating rate era: Longer horizons, alternative expectations, and emerging markets. Journal of Money and Finance, 25, 7-21. http://dx.doi.org/10.1016/j.jimonfin.2005.10.003

Chinn, M. D., \& Hiro, I. (2008). A new measure of financial openness. Journal of Comparative Policy Analysis, 10(3), 309-322. http://dx.doi.org/10.1080/13876980802231123

Chinn, M. D., \& Meredith, G. (2005). Testing uncovered interest parity at short and long horizons during the post-Bretton Woods era. NBER Working Paper, No. 11077. Washington, DC.

Ehrmann, M., \& Tzamourani, P. (2012). Memories of high inflation. European Journal of Political Economy, 28, 174-191. http://dx.doi.org/10.1016/j.ejpoleco.2011.11.005

Flood, R. P., \& Rose, A. K. (2001). Uncovered interest parity in crisis: The interest rate defense in the 1990s. IMF Working Paper 01/207.

Frankel, J., \& Poonawala, J. (2010). The forward market in emerging currencies: Less biased than in major currencies. Journal of International Money and Finance, 29(3), 585-598. http://dx.doi.org/10.2139/ssrn.1474849

Froot, R. P., \& Thaler, R. H. (1990). Anomalies: Foreign exchange. Journal of Economic Perspectives, 4(3), 179-192. http://dx.doi.org/10.1257/jep.4.3.179

Hanim, N., Salleh, M., \& Sarmidi, T. (2011). Time horizon and uncovered interest parity in emerging economies. Asian Academy of Management Journal, 16(2), 107-130.

Masawe, J. L. (2001). The monetary policy framework in Tanzania. Paper presented at the conference on 
Monetary Policy Frameworks in Africa, held at the South African reserve bank, 17-19 September 2001.

Melander, O. (2009). Uncovered interest parity in a partially dollarized developing country: Does UIP hold in Bolivia? (And If not, why not?). Ph.D. dissertation. Stockholm school of Economics.

Musinguzi, P., \& Katarikawe, M. (2001). Monetary policy frameworks in Africa: The case of Uganda. Bank of Uganda.

Poghosyan, T., Kocenda, E., \& Zemcik, P. (2008). Modeling foreign exchange risk premium in Armenia. Emerging Markets Finance and Trade, 44(1), 41-61. http://dx.doi.org/10.2753/REE1540-496X440103

\section{Notes}

Note 1. See Chinn (2006) for a summary of these results.

Note 2. Bansal and Dahlquist (2000) and Flood and Rose (2001) are early contribution in this literature.

Note 3. See Frankel and Poonawala (2010).

Note 4. Note that the depreciation of the exchange rate of the local currency is represented as increase in S.

Note 5. See Alper et al. (2009) for more detailed discussion of these issues.

Note 6. A comprehensive survey of these studies can be found in Sarno and Taylor (2002), Sarno (2005), Chinn (2006).

Note 7. For a comprehensive survey of this literature see Alper et al. (2009).

Note 8. Statements from both Barclay's and standard and charter's show that one can only make free cash withdrawal from saving account once every three months. So, I will treat the savings account as a time deposit rate with three-month maturity. At the same time, customers can withdraw money early with some penalty.

Note 9. See Poghosyan et al. (pp. 44-47), Melander (pp.106-107), and Frankel and Poonawala (pp.11).

Note 10. Note that we do not use data from Uganda because we find that while exchange rate depreciations is a stationary variable, interest rate differences are not, i.e. foreign interest rates and domestic interest rates are not cointegrated.

Note 11. See Chinn and Meredith (2005).

Note 12. See Hanim et al. (2011).

\section{Appendix A}

Table A1. Inflation, capital openness, and GDP per capita in Uganda, Tanzania, Bolivia, and Armenia

\begin{tabular}{lccccc}
\hline Country & Average inflation & Inflation variance & GDP per capita & (KAOPEN) & $\begin{array}{c}\text { Monthly U.S. } \\
\text { dollar traded }\end{array}$ \\
\hline Uganda & 7.8 & 5.25 & 1091.35 & 2.44 & 541.01 \\
Tanzania & 7.93 & 3.5 & 1256.1 & -1.17 & 116.22 \\
Armenia & 4.14 & 2.93 & 5159.17 & 2.44 & 401.61 \\
Bolivia & 5.2 & 3.5 & 4251.62 & 1.3 & 72.16 \\
\hline
\end{tabular}

Note. Inflation for all countries is based on the consumer price index of all consumption items where $2005=100$ and covers the period 2000-2012. Inflation volatility is measured by standard deviation of inflation. The source for inflation data is the IFS (international financial statistics of the IMF). GDP per capita is in PPP (current international dollar) and the source for GDP data is World Development Indicators and Global Development Finance. Financial openness index (KAOPEN) is from the Chinn-Ito index and can be found at http: //web.pdx.edu/ ito/Chinn - Itow ebsite.htm. Monthly U.S. dollar traded measures the liquidity of the foreign exchange market in the country. The sources are central banks of the respective countries. 
Table A2. Unit root test Tanzania

\begin{tabular}{|c|c|c|c|c|c|c|}
\hline \multirow[b]{2}{*}{ Variable } & \multicolumn{2}{|c|}{ Shilling U.S. dollar } & \multicolumn{2}{|c|}{ Shilling South Africa rand } & \multicolumn{2}{|c|}{$\begin{array}{c}\text { Tanzania shillings Kenya } \\
\text { Shillings }\end{array}$} \\
\hline & $\mathrm{ADF}$ & $\mathrm{pp}$ & $\mathrm{ADF}$ & $\mathrm{pp}$ & $\mathrm{ADF}$ & $\mathrm{pp}$ \\
\hline \multirow[t]{2}{*}{ Threemonths } & -2.25 & -2.96 & -2.63 & -2.5 & -3.35 & -2.45 \\
\hline & -0.188 & -0.039 & -0.086 & -0.12 & -0.013 & -0.14 \\
\hline \multirow[t]{2}{*}{ Sixmonths } & -3.3 & -2.76 & -2.76 & -2.59 & -3.42 & -2.5 \\
\hline & -0.015 & -0.065 & -0.063 & -0.091 & -0.011 & -0.12 \\
\hline \multirow[t]{2}{*}{ Twelvemonths } & -2.86 & -2.8 & -3.17 & -2.31 & -3.34 & -2.78 \\
\hline & -0.05 & -0.058 & -0.022 & -0.169 & -0.012 & -0.065 \\
\hline \multirow[t]{2}{*}{ Threemonths depreciation } & -3.92 & -4.33 & -3.68 & -4 & -4.23 & -4.51 \\
\hline & -0.002 & -0.0004 & -0.004 & -0.001 & -0.001 & -0.002 \\
\hline \multirow[t]{2}{*}{ Sixmonths depreciation } & -3.66 & -3.49 & -3.77 & -2.93 & -3.86 & -3.81 \\
\hline & -0.005 & -0.008 & -0.003 & -0.043 & -0.002 & -0.003 \\
\hline \multirow[t]{2}{*}{ Twelvemonths depreciation } & -2.67 & -2.59 & -2.92 & -2.02 & -2.55 & -2.65 \\
\hline & -0.079 & -0.096 & -0.043 & -0.277 & -0.094 & -0.083 \\
\hline
\end{tabular}

Note. ADF stands for the estimated beta coefficient in an augmented Dickey-Fuller test. PP stands for the estimated beta coefficient in the Phillips Perron stationarity test. Values in parentheses are P-values.

\section{Copyrights}

Copyright for this article is retained by the author(s), with first publication rights granted to the journal.

This is an open-access article distributed under the terms and conditions of the Creative Commons Attribution license (http://creativecommons.org/licenses/by/3.0/). 